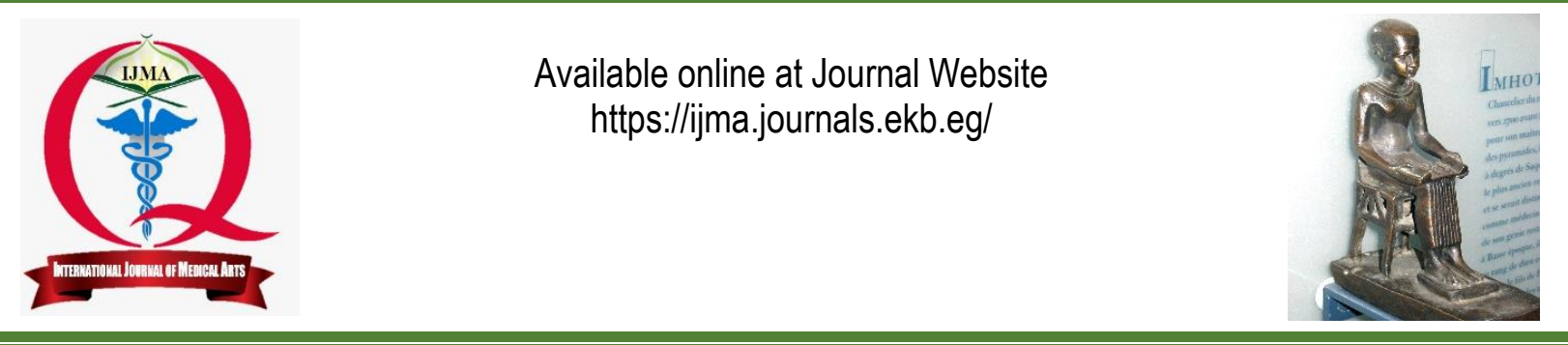

Original article

\title{
Plasma Homocysteine level in Children under Treatment with Antiepileptic Drugs and its Relation to Intelligence Quotient
}

\author{
Mohammed Abo Al-maatya; Mohamed Elmazahya; Tarek Mustafa Emran ${ }^{\mathbf{b}}$; Hany El-khaleegy ${ }^{\mathbf{a}}$ \\ Department of Pediatrics, Damietta Faculty of Medicine, Al-Azhar University, Egypt [a]. \\ Department of Clinical Pathology, Damietta Faculty of Medicine, Al-Azhar University, Egypt [b].
}

Corresponding author: Mohammed Abo Al-maaty

Email: dr_mohamed8494@yahoo.com

Received at: September 15, 2019; Revised at: December 28, 2019; Accepted at: January 6, 2020; Available online at: January 6, 2020

\section{ABSTRACT}

Background: Epilepsy is one of the most common neurological disorders in children. It often requires long-term antiepileptic drug [AED] therapy. AEDs are frequently associated with cognitive and behavioral dysfunctions. Also, there is a relationship between AEDs use and homocysteine levels. Elevated homocysteine has been associated with cognitive dysfunction. However, such effect among epileptic children has not been well-studied.

Aim of the work: To study plasma homocysteine level in children under treatment with AEDs and its relation to intelligence quotient [IQ].

Patients and methods: A case control study included 56 epileptic children on AED therapy for at least 6 months, and 36 healthy children [Controls]. Study was conducted at Al-Azhar University Hospital [Damietta] from June 2016 to June 2018. Plasma homocysteine was measured using Enzymatic Recycling [Biotecnica Instruments SpA]. IQ testing was conducted using Stanford-Binet Intelligence Scales, Fifth Edition.

Results: Epileptic children exhibited significant elevation of Homocysteine level [P=0.005], and significant affection of all IQ parameters. There was significant negative correlation between homocysteine level with total working memory, total verbal IQ and total IQ. Multivariate regression analysis revealed that homocysteine showed a significant and independent association with total working memory, total verbal IQ and total IQ. None of the other studied factors revealed such association.

Conclusion: Homocysteine was a significant and independent risk factor for low total working memory score, low total Verbal IQ and low total IQ scores. Further studies are required to confirm these results, and to evaluate the effect of homocysteine-lowering treatment on cognitive function in epileptic children.

Keywords: Epilepsy; Antiepileptic drugs; Homocysteine; Cognition; Intelligence Quotient.

This is an open access article under the Creative Commons license [CC BY] [https://creativecommons.org/licenses/by/2.0/]

Please cite this article as: Abo Al-maaty M, Elmazahy M, Emran TM, El-khaleegy H. Plasma Homocysteine level in Children under Treatment with Antiepileptic Drugs and its Relation to Intelligence Quotient. IJMA 2020; 2[1]: 223-231. 


\section{INTRODUCTION}

Epilepsy is a disorder of the brain characterized by a continuing predisposition to generate seizures and by cognitive, neurobiologic, psychological and social consequences of this condition [1]. Epilepsy is one of the most common serious neurological disorders predominant in childhood [2]. It is a highly stigmatizing disorder and a widely prevalent noncommunicable disease ${ }^{[3]}$.

The lifetime accumulative incidence of epilepsy is $3 \%$, and more than half of the seizures start in children. The prevalence of epilepsy is $0.5-1.0 \%$ annually [4].

In Egypt, the incidence of epilepsy was estimated to be 82.7 per 100,000 populations per year ${ }^{[5]}$, while the prevalence among children $6-14$ years was $7.2 / 1000[6]$.

Epilepsy frequently requires long-standing therapy with antiepileptic drugs [AED]. Unfortunately, prolonged intake of these drugs is associated with adverse psychiatric and behavioral effects [7].

Antiepileptic drugs are utilized worldwide by millions of people for treatment of epilepsy, and in many other psychiatric and neurological diseases. They are frequently associated with adverse effects, which have an impact on the tolerability and success of treatment $[8]$.

Homocysteine [Hcy] is an amino acid containing sulfur. It plays an essential role in methionine metabolism. High levels of Hcy may be due to deficiency of cofactors [folate, vitamins B12 and B6], or genetic polymorphisms of the vital metabolic enzymes ${ }^{[9]}$.

Cognitive impairment associated with epilepsy may be due to the effect of epileptic syndrome as such or as a side effect produced by AEDs [10].

On the contrary, the increased plasma Hcy levels might have a supplementary role for longterm side effects prompted by AED therapy including those affecting cognitive functions ${ }^{[11]}$.

High homocysteine levels have been linked with cognitive deficiency in many conditions [12].

However, homocysteine levels in children under treatment with antiepileptic drugs yielded conflicting results [13].
In addition, the effect of homocysteine on cognitive impairment among children with epilepsy has not been well-studied yet [11].

\section{AIM OF THE STUDY}

We aimed at evaluating the levels of homocysteine among a sample of epileptic children receiving antiepileptic drug therapy for more than six months, and to elucidate the relation between homocysteine level and cognitive dysfunction among those patients. In addition, we studied the influence of various factors [such as severity of epilepsy, types of seizures and number of AEDS] on the relation between homocysteine and IQ measurements.

\section{PATIENTS AND METHODS}

The present case control study included 56 epileptic children on antiepileptic drug treatment for at least 6 months, and 36 healthy children [controls]. Subjects were recruited from Pediatric outpatient clinic and inpatient ward at local hospital corresponding to Al-Azhar University at New Damietta within the period from June 2016 to June 2018.

The inclusion criteria encompassed the following: 1] age: 4-16 years, 2] sex: both sexes, 3] children diagnosed as having "genetic" or "unknown" epilepsy, 4] use of antiepileptic drugs for more than 6 months. Diagnosis of epilepsy is based on the practical clinical definition of epilepsy modified by ILAE[14].

Etiological classification was used according to the new ILAE Classification of the Epilepsies [15]. Patients having other etiologies of epilepsy [structural, metabolic, infectious or immune], had disorders that may affect cognition or having disorders that may affect homocysteine level [chronic kidney disease, hypothyroidism and malignancies] were excluded.

Careful history was obtained, including personal, family history, seizures history [age of first attack, history of febrile seizures, type of seizures, frequency and severity]. History of AEDs: duration of treatment, number of drugs and type, and possible side effects. Type of seizures was recorded according to new ILAE operational classification [16].

Frequency of seizures was classified as: 1] no 
seizure for $\geq 1$ year, 2] one seizure per year, 3] one seizure per month to every 6 months or 4] daily to weekly seizure [17].

Severity of seizures was determined through a set of outcomes including 1] the need for emergency department visits or hospitalizations in the past year resulting from uncontrolled seizures, 2] seizures-related injury in the last year, and 3] time since last seizure [18].

For plasma Hcy, blood samples were collected under complete aseptic conditions. Plasma was immediately separated by centrifugation at $800 \mathrm{~g}$ for $10 \mathrm{~min}$. Samples were stored at $-20{ }^{\circ} \mathrm{C}$ until transported to the laboratory using cold chain. The reagent used is a diagnostic reagent "Liquid Reagents - ready to use" for in vitro quantitative detection of total L-Homocysteine in human serum or plasma using photometric systems [Biotecnica Instruments S.p.A., Rome, Italy] through "Enzymatic Recycling". According to Di Rosa et al. [11], the cut-off value for normal level of Hcy for children is $9 \mu \mathrm{mol} / \mathrm{L}$.

Assessment of $I Q$ was done using StanfordBinet Intelligence Scales, Fifth Edition. It provides broad coverage of five fields of cognitive skills: 1] fluid reasoning, 2] knowledge, 3] quantitative reasoning, 4] visual-spatial processing and 5] working memory [19].

Ethical consideration: The aim of the study was clearly clarified, and informed consent was received from parents of the children before sharing in the study. The study was approved by our local ethical committee.

Statistical analysis: statistical analysis was performed using statistical package for social sciences [SPSS] version 19 [SPSS Inc, Chicago, USA]. Testing for normal distribution was done by Kolmogorov-Smirnov and Shapiro-Wilk tests. For comparison between numerical groups, the independent samples [t] test, Mann-Whitney, Kruskal Wallis test or one-way ANOVA tests were used. For comparison between categorical groups, the Chi square or Fisher's exact tests were used. Pearson's $r$ correlation co-efficient was used for correlating parametric continuous variables. Spearman's $\rho$ [rho] correlation co-efficient was used for correlating ordinal and non-parametric variables. Univariate linear regression analysis was made for investigating the causal relationship between IQ scores and distinctive variables. Multivariate regression models were built to validate the possible dependence of IQ scores on various factors. For all tests, $P$ values $<0.05$ were considered significant [20].

\section{RESULTS}

Table [1] shows general features, severity characteristics of epilepsy and antiepileptic drugs among cases group. The most frequent types of seizures were focal impaired awareness [52\%] followed by generalized motor seizures [48.2\%]; while the most frequent type of epilepsy was generalized type [48.2\%]. Most of the studied cases were on single antiepileptic drug; the most frequent used drug was valproate [46.4\%] followed by levetiracetam [37.5\%].

The distributions of drugs among patients on single AED are shown in table [1].

There was no significant difference between cases and control as regard age, gender. Cases had significant elevation of homocysteine level [8.58 \pm 1.95 vs. $7.46 \pm 1.61 ; P$ : 0.005$]$ as well as the frequency of hyperhomocysteinemia level $[P=$ 0.007]. Also, there was significant affection of all IQ parameters among cases when compared to controls with statistically significant difference [table 2]. Pearson correlation analysis revealed significant negative correlation between homocysteine level with total working memory [0.001], total verbal IQ [0.006] and total IQ [0.026]; while there was no significant correlation with other parameters [Table 3 , figure 1].

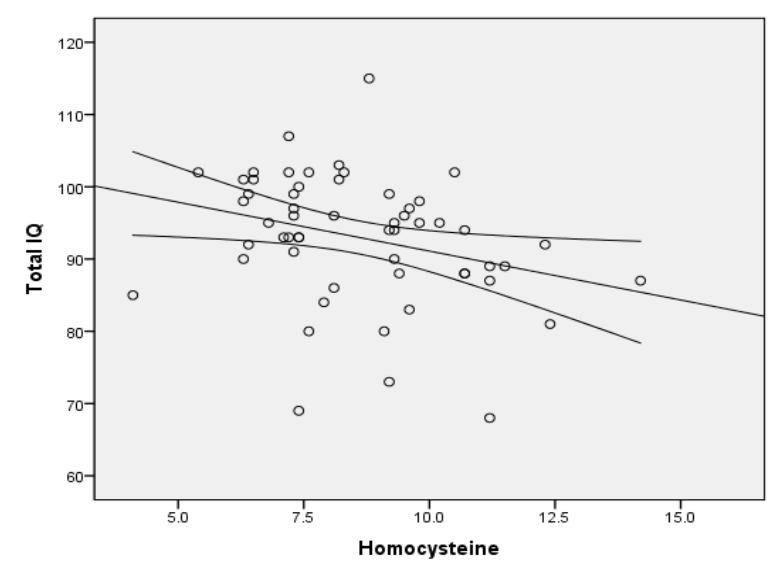

Figure [1]: Correlation between homocysteine level and total $I Q$ among cases group 
Abo Al-maaty M, et al.

Univariate linear regression analysis confirmed these results. It also demonstrated that young age at first seizure was a major risk factor for low IQ scores [Table 4]. Multivariate regression analysis revealed that homocysteine was an independent and significant risk factor for total working memory score, total Verbal $I Q$ and total $I Q$ scores. Multivariate regression model was built with use of potential risk factors [age, gender, age at first seizures, frequency of seizures, type of seizures and number of AEDs] as covariates.

Table [1]: General features, severity characteristics of epilepsy and antiepileptic drugs among cases group

\begin{tabular}{|c|c|c|}
\hline \multicolumn{2}{|c|}{ Variable } & \multirow{2}{*}{$\begin{array}{c}\text { Results } \\
4.93 \pm 2.78 ; 0.5-13\end{array}$} \\
\hline Age of first seizure [years] & Mean $\pm S D ;$ Range & \\
\hline Duration of treatment [years] & Mean $\pm S D ;$ Range & $3.59 \pm 2.36 ; 1-10$ \\
\hline Type of seizures & $\begin{array}{l}\text { Focal aware } \\
\text { Focal impaired awareness } \\
\text { Generalized motor } \\
\text { Generalized non-motor [absence] }\end{array}$ & $\begin{array}{c}5[8.9 \%] \\
28[50 \%] \\
27[48.2 \%] \\
8[14 \%]\end{array}$ \\
\hline Type of epilepsy & $\begin{array}{l}\text { Focal } \\
\text { Generalized } \\
\text { Combined }\end{array}$ & $\begin{array}{c}21[37.5 \%] \\
27[48.2 \%] \\
8[14.3 \%]\end{array}$ \\
\hline Frequency of seizures & $\begin{array}{l}\text { free } \geq 1 \text { year } \\
1 / \text { year } \\
1 / \text { month to every } 6 \text { months } \\
\text { Weekly }\end{array}$ & $\begin{array}{c}13[23.2 \%] \\
18[32.1 \%] \\
20[35.7 \%] \\
5[8.9 \%]\end{array}$ \\
\hline Time from last seizure & $\begin{array}{l}>1 \text { year } \\
6-12 \text { months } \\
1-5 \text { months } \\
1 \text { week }-1 \text { month } \\
\text { In past week }\end{array}$ & $\begin{array}{c}16[28.6 \%] \\
13[23.2 \%] \\
15[26.8 \%] \\
5[8.9 \%] \\
7[12.5 \%] \\
\end{array}$ \\
\hline Number of AEDs & $\begin{array}{l}\text { Single } \\
\text { Two } \\
\text { Three }\end{array}$ & $\begin{array}{l}27 \\
19 \\
10 \\
\end{array}$ \\
\hline Frequency of AEDs use & $\begin{array}{l}\text { Valproate } \\
\text { Levetiracetam } \\
\text { Oxcarbazepine } \\
\text { Carbamazepine } \\
\text { Topiramate } \\
\text { Phenytoin }\end{array}$ & $\begin{array}{c}26[46.4 \%] \\
21[37.5 \%] \\
16[28.6 \%] \\
14[25 \%] \\
10[17.9 \%] \\
8[14.3 \%]\end{array}$ \\
\hline
\end{tabular}

Table [2]: General characteristics, homocysteine and IQ results of studied cases

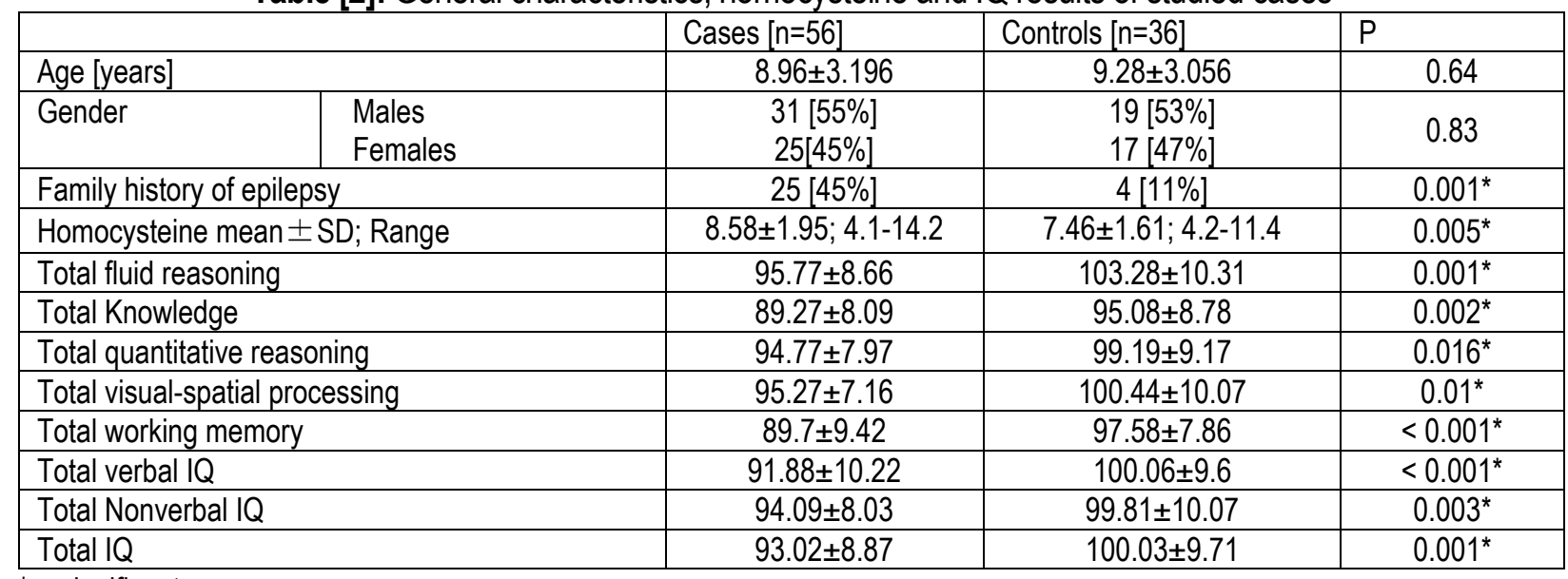

${ }^{*}=$ significant 
Table [3]: Correlation between homocysteine values and IQ among cases group

\begin{tabular}{|l|c|c|}
\hline \multirow{2}{*}{ Variables } & \multicolumn{2}{|c|}{ Homocysteine } \\
\cline { 2 - 3 } & $\mathrm{r}$ & $\mathrm{P}$ \\
\hline Total fluid reasoning & -0.197 & 0.145 \\
\hline Total Knowledge & -0.257 & 0.055 \\
\hline Total quantitative reasoning & -0.238 & 0.077 \\
\hline Total visual-spatial processing & -0.244 & 0.07 \\
\hline Total working memory & -0.423 & $0.001^{*}$ \\
\hline Total verbal IQ & -0.361 & $0.006^{*}$ \\
\hline Total Nonverbal IQ & -0.233 & 0.084 \\
\hline Total IQ & -0.297 & $0.026^{*}$ \\
\hline
\end{tabular}

Table [4]: Univariate linear regression analysis of distinctive variables in relation to IQ scores

\begin{tabular}{|l|c|c|c|c|c|c|c|c|}
\hline & Total FR & Total KN & Total QR & Total VS & Total WM & Verbal IQ & NVIQ & Total IQ \\
\hline Age & $0.006^{*}$ & 0.089 & $0.031^{*}$ & 0.11 & 0.13 & $0.011^{*}$ & 0.056 & $0.02^{*}$ \\
\hline Male gender & 0.38 & $0.004^{*}$ & 0.21 & $0.033^{*}$ & 0.19 & 0.065 & 0.061 & 0.057 \\
\hline Age at first seizure & $0.036^{*}$ & $0.006^{*}$ & $0.016^{*}$ & 0.064 & $0.003^{*}$ & $0.005^{*}$ & $0.007^{*}$ & $0.004^{*}$ \\
\hline Duration of treatment & 0.36 & 0.52 & 0.89 & 0.97 & 0.21 & 0.98 & 0.84 & 0.89 \\
\hline Number of AEDs & 0.87 & 0.21 & 0.31 & 0.52 & $0.008^{*}$ & 0.13 & 0.48 & 0.24 \\
\hline Focal seizures & $0.014^{*}$ & 0.2 & 0.074 & $0.014^{*}$ & 0.13 & 0.056 & 0.051 & $0.038^{*}$ \\
\hline Frequency of seizures & 0.98 & 0.12 & 0.31 & 0.36 & $0.032^{*}$ & 0.26 & 0.24 & 0.25 \\
\hline Time from last seizure & 0.94 & 0.09 & 0.27 & 0.19 & $0.033^{*}$ & 0.23 & 0.093 & 0.17 \\
\hline Homocysteine & 0.145 & 0.055 & 0.077 & 0.07 & $0.001^{*}$ & $0.006^{*}$ & 0.084 & $0.026^{*}$ \\
\hline
\end{tabular}

${ }^{*}=$ significant

\section{DISCUSSION}

Antiepileptic drugs are the mainstay of epilepsy therapy [21]. Taking AEDs might affect cognitive and behavioral functions [22]. On the other hand, high homocysteine levels have distinctive direct effects on the CNS, and many of these effects are separate from vascular injury [23].

In the present study, Hcy level was significantly elevated among cases compared to controls, which was found by many authors. Verrotti et al.[24] found that patients received valproic acid or carbamazepine as a single drug for one year exhibited significant increase of Hcy concentrations, compared with pretreatment levels and control values. El-Farahaty et al. [25] reported significantly higher Hcy means in 96 patient received antiepileptic drugs versus control $[P<0.001]$. Ni et al. [26]'s meta-analysis concluded that monotherapy with sodium valproate is associated with the increase in plasma Hcy levels. No significant differences were present in relation to ethnicity or age. Also, a recent study, with suitable sample size, enrolled 112 children [2-12 years] with epilepsy receiving phenytoin or carbamazepine as a single drug for more than six months, revealed significantly higher concentration of $\mathrm{Hcy}$ in the study group compared with the control group [27].

On the contrary, an Egyptian study found nonsignificant difference regarding the plasma Hcy levels between 60 patients with idiopathic epilepsy and 30 healthy children [controls] [28]. Also, Ünal et al. [29] investigated thrombophilic risk factors among 21 epileptic children [1-13 years] treated with valproic acid monotherapy. Elevation in Hcy levels was observed, but without statistical significance. Finally, Ramazan et al. [30] included forty-seven idiopathic epileptic patients treated with valproic acid, levetiracetam or lamotrigine, compared with 38 age-matched healthy controls. There was no significant difference between patient and control values. Thus, the effects of AEDs on plasma homocysteine levels seems to be more prominent among patients receiving polytherapy; however, the majority the above-mentioned studies, including the present one, had low sample sizes [concerning patients on AED monotherapy], and such findings need further confirmation.

Antiepileptic drugs increase Hcy concentration by interfering with the absorption of cofactors [folic acid and vitamin B12], which are necessary for its remethylation, and by induction of hepatic enzymes, which regulate the level of folate. In addition, the 
metabolism of AEDs, especially hydroxylation, rises the utilization of folate, which in turn is associated with elevated Hcy [22]. Thus, the resulted low folate and vitamin B12 are the main causes of elevated Hcy. We cannot know if this state of low vitamins was present before administration of AEDs or not; however, we excluded all patients with abnormal neurological examination and patients with potential hyperhomocysteinemia.

As regard to $I Q$ measurement, there was significant affection of all IQ parameters among cases when compared to controls. Cognitive impairments are more frequent among children with epilepsy. The causes of such impairment often multifactorial; contributing factors include epileptic syndrome, type and frequency of seizures, age at onset, and duration and types of treatment[31]. There is an element of intrinsic cognitive dysfunctions linked to the primary structural brain problem; however, there are more variable factors affecting cognition including the frequency and types of seizure, the use of AEDs, and psychiatric comorbidities [32]. The effect of poor control of seizures on cognitive functions deterioration and the proposed mechanisms is unclear [33]. In many epilepsy syndromes, cognitive dysfunctions are unrelated to the frequency of seizures; in addition, these dysfunctions usually precede the onset of seizure and continue despite abstinence of seizures[34].

In the present study, we excluded patients suffering from symptomatic epilepsy so as to have a group with no obvious other etiologies of epilepsy that may have cognitive impairment. Although clinical, electroencephalographic, and radiological factors support the diagnosis of "unknown epilepsy", the underlying undiagnosed pathology may vary between patients.

In the present study, homocysteine level was negatively correlated with total working memory, total verbal IQ and total IQ scores, which was confirmed through univariate regression analysis; furthermore, multivariate regression model for homocysteine, with the use of age, gender, age at first seizures, frequency of seizures, type of seizures and number of AEDs as covariates, revealed that homocysteine was an independent and significant risk factor for total working memory score, total Verbal IQ and total IQ scores.

The disorders of CNS related to increased homocysteine might be illuminated by three possible mechanisms. First, Hcy may lead to direct neurotoxicity, by promoting oxidative stress. Second, a metabolic disturbance in Hcy metabolism may change neurotransmitter synthesis. Finally, homocysteinemia association with occlusive vascular disease might be mediated through blood vessel wall damage or impaired blood coagulation [35]. Through the combination of these results with the hypothesis that $\mathrm{HHcy}$ is a modifiable risk factor for cognitive dysfunctions, it was necessary to investigate the potential role of such important factor among a considerable number of children in our community.

Studies discussing this topic are scarce among pediatric population, and yielded variable results $[36$, 37]. Thus, short-term effects of homocysteine on developing brain are not well studied yet; moreover, it is probable that IQ impairment may need many decades to be observed, and it would not be recognized in a young cohort.

There is only one study that previously evaluated Hcy contribution in declining cognitive function among patients with epilepsy, and was published by Di Rosa et al. [11]. In this study, they reported that there was no relation between Hcy and IQ. However, they only measured verbal IQ, total IQ, and performance IQ, obtained by Wechsler Intelligence Scale. The present study is different in estimating various aspects of cognitive development including subsets of five cognitive domains, which resulted in proposal of the effect of Hcy on working memory function. In addition, Di Rosa et al. [11] study included patients up to 25 years of age, while the upper limit of our patients was 16 years. Knowing the strong effect of low age in the present study on studied outcomes may explain the resulted differences. Univariate linear regression of various potential risk factors associated with $I Q$ scores revealed that younger children, early age at first seizures are the main contributing factors independent of homocysteine levels. In contrast, the increased frequency of seizure was a risk factor for low total working memory with dependence on homocysteine level. 
The cognitive and the behavioral effect of AEDs is linked with those of seizures and many other elements may also have effects on cognition and behavior, such as epilepsy etiology, seizure type, frequency, and duration age at onset of seizures, and electroencephalographic pattern [38]. However, where AED withdrawal were associated with improved postoperative IQ scores and gain in $I Q$, independent of other determinants of cognitive outcome[39], AEDs might constitute some independent effects as shown in a study of 301 patients who were subjected to neuropsychological assessment before and soon after epilepsy surgery.

In the present study, patients with predominant generalized seizures displayed reduction of all IQ test parameters compared to patients with predominant focal seizures. In contrast, there was no significant relation to Hcy level. Rathouz et al.[40] found that children with new onset idiopathic generalized epilepsy had low significant reduction of intelligence scores compared with children with localization-related epilepsy. Also, Reilly et al.[41] found an association between intellectual disability and predominant generalized seizures.

It has been suggested that seizures involving the entire brain may be more harmful contrasted with seizures affecting specific region, which are associated with more particular cognitive injuries [42]. In addition, poor cognitive outcome has been observed with generalized seizures [43].

One of the strength points of the present study was not only relaying on the total IQ and its two main components; verbal IQ and non-verbal IQ as measures of cognitive abilities, but also detailed tests for memory and reasoning were performed, and have revealed significant results. Moreover, the present study included multiple potential risk factors including severity of epilepsy, reported side effects of the parents, and duration of treatmen.

In contrast, the major limitation of the present study is lack of evaluating the homocysteine genetic polymorphism to verify the relation between elevated homocysteine level and the presence of such genetic variation. Moreover, the crosssectional design of the study might withhold the long-term effects of Hcy. Finally, IQ evaluation and Hcy measurement were assessed throughout the treatment period, and not at the onset of seizures and/or AED treatment. Thus, it was not possible to compare between these parameters at various durations; in addition, long-term follow-up was unavailable.

\section{Conclusions}

Epileptic children exhibited significant elevation of homocysteine, and significant affection of all IQ parameters. Homocysteine was a significant and independent risk factor for low total working memory score, low total Verbal IQ and low total IQ scores in the present study. The effects of elevated homocysteine levels on IQ score are more obvious among younger patients, early age at first seizure, patients with focal seizures and those on multiple therapies, and require special attention on evaluation. Thus, close monitoring of epileptic patients on antiepileptic drug therapy for various aspects of cognitive function are needed. Further studies are required to confirm these results, and to evaluate the effect of homocysteine-lowering treatment on cognitive function in epileptic children.

\section{Financial and Conflict of interest disclosure}

Authors declare that there was no conflict of interest.

\section{REFERENCES}

1- Agarwal MM. To record clinico-etiological profile of children with epilepsy-A clinical study. J Adv Med Dent Sci Res. 2019;7[8]:88-91. [DOI:10.21276/ jamdsr].

2- Pandey S, Singhi P, Bharti B. Prevalence and treatment gap in childhood epilepsy in a north Indian city: a community-based study. J Trop Pediatr. 2014;60[2]:118-123. [DOI: 10.1093/tropej/ fmt091].

3- Njamnshi AK, Tabah EN, Yepnjio FN, Angwafor SA, Dema F, Fonsah JY, et al. General public awareness, perceptions, and attitudes with respect to epilepsy in the Akwaya Health District, SouthWest Region, Cameroon. Epilepsy Behav. 2009; 15:179-85. [DOI:10.1016/ j.yebeh.2009.03.013].

4- Mikati MA, Tchapyjnikov D. Seizures in Childhood. In: Kliegman RM, St Geme JW, Blum NJ, Shah SS, Tasker RC, Wilson KM [Eds], Nelson Textbook of Pediatrics, 21th Ed. Philadelphia, PA: Elsevier. 2019, pp. 3086-3120. 
5- El-Tallawy HN, Farghaly WM, Rageh TA, Shehata GA, Metwally NA, Badry R, et al. Spectrum of epilepsy-prevalence, impact, and treatment gap: an epidemiological study from alQuseir, Egypt. Neuropsychiatr Dis Treat. 2016; 12:1111-1118. [DOI: 10.2147/NDT.S87765].

6- Alshahawy AK, Darwish AH, Elsaid Shalaby S, Mawlana W. Prevalence of idiopathic epilepsy among school children in Gharbia Governorate, Egypt. Brain Dev. 2018;40[4]:278-286. [DOl: 10.1016/j. braindev. 2017. 12.009].

7- Lee HS, Wang SY, Salter DM, Wang CC, Chen SJ, Fan HC. The impact of the use of antiepileptic drugs on the growth of children. BMC Pediatr. 2013; 13:211. [DOI: 10.1186/1471-2431-13-211].

8- Gaitatzis A, Sander JW. The long-term safety of antiepileptic drugs. CNS Drugs 2013; 27[6]:43555. [DOI: $10.1007 / \mathrm{s} 40263-013-0063-0]$.

9- Belcastro V, Striano P. Antiepileptic drugs, hyperhomocysteinemia and B-vitamins supplementation in patients with epilepsy. Epilepsy Res. 2012; 102[1-2]:1-7. [DOI: 10.1016/ j.eplepsyres. 2012. 07.003].

10- Jackson DC, Dabbs K, Walker NM, Jones JE, Hsu DA, Stafstrom CE, Seidenberg M, Hermann BP. The neuropsychological and academic substrate of new/recent-onset epilepsies. J Pediatr 2013; 162[5]:1047-53. [DOI: 10.1016/j.jpeds. 2012. 10.046].

11- Di Rosa G, Lenzo P, Parisi E, Neri M, Guerrera S. Role of plasma homocysteine levels and MTHFR polymorphisms on IQ scores in children and young adults with epilepsy treated with antiepileptic drugs. Epilepsy Behav. 2013; 29[3]: 548-51. [DOI: 10.1016/j.yebeh.2013.09.034].

12- Ford AH, Almeida OP. Effect of Vitamin B Supplementation on Cognitive Function in the Elderly: A Systematic Review and Meta-Analysis. Drugs Aging. 2019;36[5]:419-434. [DOI: 10.1007/ s40266-019-00649-w].

13- Prasad DK, Prabhakararao TS, Satyanarayana U, Prabha TS, Munshi A. Association of Serum Homocysteine and hs-CRP with Idiopathic Generalized Epilepsy and Duration of Antiepileptic Drug Therapy. J Clin Diagnost Res. 2018;12[2]:15. [DOI: 10.7860/JCDR/2018/30001.11148].

14- Fisher RS, Acevedo C, Arzimanoglou A, Bogacz A, Cross JH, Elger CE, et al. ILAE official report: a practical clinical definition of epilepsy.
Epilepsia. 2014; 55[4]: 475-82. [DOI: 10.1111/ epi.12550].

15- Scheffer IE, Berkovic S, Capovilla G, Connolly $M B$, French J, Guilhoto L, et al. ILAE classification of the epilepsies: Position paper of the ILAE Commission for Classification and Terminology. Epilepsia. 2017;58 [4]: 512-521. [DOI: 10.1111/epi.13709].

16- Fisher RS, Cross JH, D'Souza C, French JA, Haut SR, Higurashi N, et al. Instruction manual for the ILAE 2017 operational classification of seizure types. Epilepsia. 2017; 58[4]:531-42. [DOI:10.1111/epi. 13671].

17- O'Donoghue MF, Duncan JS, Sander JW. The subjective handicap of epilepsy. A new approach to measuring treatment outcome. Brain. 1998;1 21 [Pt 2]: 317-43. [DOI: 10.1093/brain/121.2.317].

18- Choi H, Hamberger MJ, Munger Clary H, Loeb R, Onchiri FM, et al. Seizure frequency and patient-centered outcome assessment in epilepsy. Epilepsia. 2014;55[8]:1205-1212. [DOI: 10.1111/ epi.12672].

19- Roid GH. Stanford-Binet Intelligence Scales-Fifth Edition. Itasca, IL: Riverside Publishing. 2003.

20- Kirkwood BR, Sterne JAC. Essential Medical Statistics 2003; $2^{\text {nd }}$ Edition, Blackwell Science, Inc., 350 Main Street, Malden, Massachusetts 021485020, USA.

21- Abou-Khalil BW. Update on Antiepileptic Drugs 2019. Continuum [Minneap Minn]. 2019;25[2]:508536. [DOI: $10.1212 / C O N .0000000000000715]$.

22- Sarecka-Hujar B, Szoltysek-Bołdys I, Kopyta I, Dolińska B, Sobczak A. Concentrations of the Selected Biomarkers of Endothelial Dysfunction in Response to Antiepileptic Drugs: A Literature Review. Clin Appl Thromb Hemost. 2019;25:1-9. [DOI: 10.1177/1076029619859429].

23- Smith AD, Warren MJ, Refsum H. Vitamin B12. Adv Food Nutr Res. 2018; 83:215-279. [DOI: 10.1016/bs.afnr.2017.11.005].

24- Verrotti A, Pascarella R, Trotta D, Giuva T, Morgese G, Chiarelli F. Hyperhomocysteinemia in children treated with sodium valproate and carbamazepine. Epilepsy Res. 2000; 41:253-7. [DOI: 10.1016/s0920-1211[00]00150-9].

25- El-Farahaty RM, El-Mitwalli A, Azzam H, Wasel Y, Elrakhawy MM, Hasaneen BM. Atherosclerotic effects of long-term old and new antiepileptic drugs 
monotherapy: a cross-sectional comparative study. J Child Neurol. 2015;30 [4]:451-7. [DOI: 10.1177/ 0883073814551388].

26- Ni G, Qin J, Fang Z, Chen Y, Chen Z, Zhou J, Zhou L. Increased homocysteine levels in valproate-treated patients with epilepsy: a metaanalysis. BMJ open. 2014;4[7]:e004936. [DOI: 10.1136/bmjopen-2014-004936].

27- Chandrasekaran S, Patil S, Suthar R, Attri SV, Sahu JK, Sankhyan N, et al. Hyperhomocysteinemia in children receiving phenytoin and carbamazepine monotherapy: a cross-sectional observational study. Arch Dis Child. 2017; 102 [4]: 346-51. [DOI: 10.1136/archdischild-2016-311436].

28- Nour Eldeen O, Eldayem SA, Shatla RH, Omara NA, Elgammal SS. Homocysteine, folic acid and vitamin B12 levels in serum of epileptic children. Egyptian J Med Hum Genet. 2012;13[3]:275-80. [DOI: 10.1016/j.ejmhg.2012.05.002].

29- Ünal Ö, Deda G, Teber S, Ertem M, Akar N. Thrombophilic Risk Factors in Epileptic Children Treated with Valproic Acid. Pediatr Neurol. 2009; 40 [2]: 102-106. [DOI: 10.1016/j.pediatrneurol. 2008.10.005].

30- Ramazan DÇ, Anadol Ü, Yalçın AD, Yalçın AS. Plasma homocysteine and aminothiol levels in idiopathic epilepsy patients receiving antiepileptic drugs. Turk J Biochem. 2019; 44[2]: 1-6 [DOI: 10.1515/ tjb-2018-0218].

31- Carreño M, Donaire A, Sánchez-Carpintero R. Cognitive disorders associated with epilepsy: diagnosis and treatment. Neurologist 2008; 14 : S26-34 [DOI: 10.1097/01.nrl.0000340789. 15295. $8 \mathrm{f}$.

32- Mula M, Cock HR. More than seizures: improving the lives of people with refractory epilepsy. Eur $\mathrm{J}$ Neurol. 2015;22[1]:24-30. [DOI: 10.1111/ ene. 12603].

33- Laxer KD, Trinka E, Hirsch LJ, Cendes F, Langfitt J, Delanty N, et al. The consequences of refractory epilepsy and its treatment. Epilepsy Behav. 2014; 37:59-70. [DOl: 10.1016/j.yebeh. 2014. 05.031.].

34- Blond BN, Detyniecki K, Hirsch LJ. Assessment of treatment side effects and quality of life in people with epilepsy. Neurol Clin. 2016;34[2]:395-410. [DOI: 10.1016/j.ncl.2015.11.002].
35- Setién-Suero E, Suárez-Pinilla M, Suarez-Pinilla P, Crespo-Facorro B, Ayesa-Arriola R. Homocysteine and cognition: A systematic review of 111 studies. Neurosci Biobehav Rev. 2016; 69: 280298. [DOI: 10.1016/j.neubiorev.2016.08.014].

36- Strain JJ, McSorley EM, van Wijngaarden E, Kobrosly RW, Bonham MP, Mulhern MS, et al. Choline status and neurodevelopmental outcomes at 5 years of age in the Seychelles Child Development Nutrition Study. Br J Nutr. 2013; 110 [2]: 330-336. [DOI: 10.1017/ S000711451200 5077].

37- Strand TA, Taneja S, Ueland PM, Refsum H, Bahl R, Schneede J, Sommerfelt H, Bhandari N. Cobalamin and folate status predicts mental development scores in North Indian children 12-18 mo of age. Am J Clin Nutr. 2013;97[2]:310-317. [DOI:10.3945/ajcn.111.032268].

38- Ulate-Campos A, Fernández IS. Cognitive and Behavioral Comorbidities: An Unwanted Effect of Antiepileptic Drugs in Children. Semin Pediatr Neurol. 2017;24[4]:320-330. [DOI:10.1016/ j. spen. 2017.10.011].

39- Boshuisen K, van Schooneveld MM, Uiterwaal CS, Cross JH, Harrison S, Polster T, et al. Intelligence quotient improves after antiepileptic drug withdrawal following pediatric epilepsy surgery. Ann Neurol. 2015;78[1]:104-14. [DOl: 10.1002/ana.24427].

40- Rathouz PJ, Zhao Q, Jones JE, Jackson DC, Hsu DA, Stafstrom CE, Seidenberg M, Hermann BP. Cognitive development in children with new onset epilepsy. Dev Med Child Neurol. 2014; 56[7]: 635-641. [DOI: 10.1111/dmcn.12432.].

41- Reilly C, Atkinson P, Das KB, Chin RF, Aylett SE, Burch V, et al. Neurobehavioral comorbidities in children with active epilepsy: a population-based study. Pediatrics. 2014;133[6]: e1586-93. [DOI: 10.1542/ peds.2013-3787].

42- Elger CE, Helmstaedter C, Kurthen M. Chronic epilepsy and cognition. Lancet Neurol. 2004; 3 [11]: 663-672. [DOI: 10.1016/S1474-4422 [04] 00906-8].

43- Rantanen K, Eriksson K, Nieminen P. Cognitive impairment in preschool children with epilepsy. Epilepsia. 2011;52[8]:1499-1505. [DOI: 10.1111/j. 1528-1167.2011. 03092.x]. 